\title{
Idiosincrasia, un factor clave en la transferencia tecnológica
}

Fecha de recepción: 15 de noviembre de 2016 Fecha de aprobación: 22 de diciembre de 2016 Pp. 191-212
María del Pilar Escott Mota Universidad Autónoma de Querétaro pilar_e86@hotmail.com

Luis Rodrigo Valencia Pérez ${ }^{2}$ Universidad Autónoma de Querétaro royvalper@hotmail.com

Cómo citar este artículo: Escott, M. P. y Valencia, L. R.(2016). Idiosincrasia, un factor clave en la transferencia tecnológica. Comunicación, cultura y política, 7, pp. 191-212.

\section{Resumen}

Este artículo de reflexión tiene como propósito describir el concepto de transferencia tecnológica y analizar sus principales modelos para identificar el papel que desempeña la idiosincrasia en estos. Para lograrlo, se llevó a cabo una revisión bibliográfica que consigna desde las principales acepciones del término, los modelos representativos, las fases y los factores involucrados en el proceso hasta el concepto de idiosincrasia, para, a través de una revisión descriptiva, discutir la importancia y relevancia del este concepto en la transferencia tecnológica. Es de resaltar que este artículo no agota el tema, sino que más de un lector podrá agregar nuevos elementos que contribuyan a complementarlo.

\section{Palabras clave}

Transferencia tecnológica, idiosincrasia, modelos, ciencia, tecnología.

1 Candidata a Doctora en Gestión Tecnológica e Innovación de la Universidad Autónoma de Querétaro. Magister en Administración en la Universidad Autónoma de Querétaro.

2 Doctor en Gestión Tecnológica e Innovación Universidad Autónoma de Querétaro. 


\title{
Idiosyncrasy, a key factor in technology transfer
}

\begin{abstract}
This article of reflection aims at describing the concept of technology transfer and analyze its main models in order to identify the role that idiosyncrasy plays in them. In order to achieve this, we carried out a bibliographical review which provides from the main meanings of the term, the representative models, the phases and the factors that are involved in the process, to the concept of idiosyncrasy, so that through a descriptive review, discuss the importance and relevance of this concept in technology transfer. It is worth noting that this article does not exhaust the theme, and more than one reader will have the possibility to add new elements that contribute to complement it.
\end{abstract}

\section{Keywords}

Technology transfer, idiosyncrasy, models, science, technology.

\section{L'idiosyncrasie, facteur clef dans le transfert de technologie}

\section{Résumé}

Cet article a pour objet la description du concept de transfert de technologie et l'analyse des principaux modèles d'identification du rôle joué par l'idiosyncrasie. Nous avons ainsi réalisé une analyse bibliographique déterminant les principales acceptations du terme, les modèles représentatifs, les phases et facteurs impliqués dans le processus du concept d'idiosyncrasie, avec comme objectif, au travers d'une analyse descriptive, de disserter sur l'importance de ce concept dans le transfert technologique. Notons que cet article ouvre le débat et offre au lecteur la possibilité d'ajouter de nouveaux éléments qui permettront de le compléter.

\section{Mots clés}

Transfert de technologie, idiosyncrasie, modèles, science, technologie. 


\section{Idiossincrasia, um fator-chave na transferência de tecnologia}

\section{Resumo}

Este artigo reflexivo tem como propósito descrever o conceito de transferência de tecnologia e analisar seus principais modelos para identificar o papel dessas idiossincrasias. Para isso, realizou-se uma revisão da literatura inclui desde os principais significados do termo, modelos representativos, as fases e os fatores envolvidos no processo até o conceito de idiossincrasia, para, através de uma revisão descritiva, discutir a importância e relevância deste conceito na transferência de tecnologia. É de salientar que este artigo não esgota o assunto, mas mais de um leitor pode adicionar novos elementos para complementá-lo.

\section{Palavras-chave}

Transferência de tecnologia, idiossincrasia, modelos, ciência, tecnologia. 


\section{Introducción}

1 contexto actual está enmarcado por una era tecnocientífica, la cual se Cha enfocado en el desarrollo tecnológico que ha impactado en entornos sociales, laborales, industriales, económicos, educativos, ecológicos, entre otros, e impregnado de expectativas a países en vías de desarrollo (Stiglitz, 2002; Tezanos, 2001). Lo anterior ha derivado de varias investigaciones que establecen la existencia de una correlación entre un desarrollo económico y la tecnología, asegurando que esta última, si es adecuadamente direccionada, propicia el desarrollo humano en las sociedades (Castells, 1999). Tan es así que Porter (2011), en sus factores internacionales para la competitividad de un país, precisa la existencia de un sistema de ciencia y tecnología.

Las economías neoliberales han generado un reordenamiento mundial donde los países se encuentran más estrechamente vinculados compartiendo insumos, información, conocimientos y un sistema económico global, lo cual ha sido habilitado en gran medida a los avances tecnológicos. Por ello, hoy las organizaciones apuestan por el desarrollo tecnológico o la adquisición de la tecnología centrándose en entender la que adquieren o desarrollan y saber cómo aplicarla, con el objetivo de aprovechar innovaciones o asimilar tecnologías que ya existen, lo cual hace referencia a la transferencia tecnológica (Ohmae, 1990).

Por su parte, Sosa (2014) acentúa que la transferencia tecnológica representa uno de los factores clave contemporáneos, pues permite transmitir, adquirir e intercambiar tecnologías universales entre países, con lo cual habilita una vía para detonar avances científicos y tecnológicos en un entorno cambiante con exigencias mundiales. Además, para Soto (2006), Finlandia es una claro ejemplo de una país que ha apostado por la tecnología para atomizar su economía, pues se ha avocado en crear políticas públicas para estimular la innovación, entendida esta como convertir una idea en un producto o servicio con éxito para su comercialización y un elemento clave para habilitar innovación en la transferencia tecnológica.

Esta investigación, a través de las indagaciones empíricas, pretende describir el concepto de transferencia tecnológica y analizar sus principales modelos para identificar el papel que desempeña la idiosincrasia en estos. 
Asi mismo, proporcionar al lector una puesta al día sobre conceptos que se encuentran en una constante evolución en la gestión tecnológica. Las investigaciones se han enfocado en la normativa legal de transferencia, en índices, casos de éxito, pero pocos se han dado a la tarea de ver la relación entre la tecnología y la idiosincrasia de quien adquiere, integra y la usa.

Así, inicia dando cuenta de la literatura del concepto de transferencia tecnológica y de los principales modelos de aplicación; se abordará también el concepto de idiosincrasia y su relación con la transferencia tecnológica para integrar una reflexión donde se discutirá el lugar que asume este concepto en los modelos existentes.

\section{Marco teórico}

\subsection{Concepto de transferencia tecnológica}

Son varias las acepciones que recibe el concepto de transferencia tecnológica, por ejemplo, para la United Nations Conference on Trade and Development (2003), es definida como transferir el conocimiento de una forma sistematizada, con el propósito de elaborar un producto, aplicar un proceso o prestar un servicio. Por otro lado, para la Fundación COTEC (2001), es transferir el capital intelectual y el know-how entre organismos con un puntal objetivo de crear y desarrollar productos y servicios exitosos comercialmente.

Por otro lado, para Loaiza (2004), representa difundir una tecnología ya existente desde su panorama original donde fue creada a un panorama totalmente diferente. También es considerada la actividad de gestionar la propiedad de derechos intelectuales e industriales de un organismo a través de identificar la tecnología, protegerla, explotarla y defenderla (European Commission, DG Enterprise, 2004).

Las definiciones citadas aportan visiones diferentes sobre el concepto, pero presentan factores clave que permiten integrar una definición más detallada donde se puede precisar al concepto de transferencia tecnológica como un proceso que establece acciones detalladas con el objetivo de conferir 
capacidades, habilidades, información y conocimientos para detonar una ventaja competitiva tanto a organizaciones como países, a fin de desarrollar la competitividad a través de rendimiento industrial y comercial teniendo como herramienta la I+D $+\mathrm{I}$ (United Nations Conference on Trade and Development, 2003; Fundación COTEC, 2003; Becerra, 2004; European Commission, DG Enterprise, 2004; Aceytuno y Cáceres, 2012).

\subsection{Modelos de transferencia tecnológica}

En esta sección, se abordarán modelos de transferencia tecnológica considerados los más representativos de acuerdo con la literatura revisada, como es el modelo de transferencia tecnológica lineal, el modelo dinámico, el modelo de la triple hélice, el modelo latinoamericano, modelo pentahélice y finalmente el modelo European Technology Transfer Guide to Best Practice.

\subsection{Modelo lineal}

El modelo lineal de transferencia tecnológica, según Smith (1995), se enfoca en la necesidad del mercado haciendo investigación básica para posteriormente traducirla en investigación aplicada que permitirá accionar el proceso de transferencia del resultado generado de la investigación, es decir, que, para que nuevos productos y servicios sean insertos en mercado, se establecen varias fases que comienza con investigación científica, y es de aquí que surge la denominación lineal, puesto que supone que, según las actividades de $\mathrm{I}+\mathrm{D}$, es posible incorporar nuevos productos o servicios; esto mismo se aplica para las propuesta de nuevos procesos de fabricación o su modificación. El modelo ha sido indicado como nacido de la investigación básica, puesto que no presenta elementos y operaciones catalizadores para procesar la transferencia de los resultados generados en la investigación a las organizaciones (Smith, 1995; García, Gualdrón y Bolívar, 2013) (figura 1). 
Figura 1. Modelo lineal.

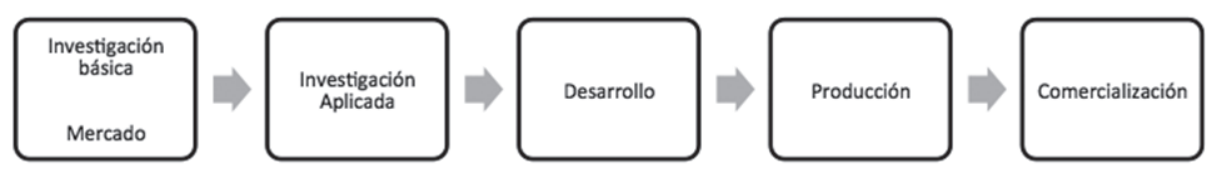

Fuente. Smith (1995) y García, Gualdrón y Bolívar (2013).

\subsubsection{Modelo dinámico}

A la evolución del modelo lineal surge el dinámico con una estructura más compleja que incluye nuevos elementos y procedimientos enfocados desde el punto de vista del investigador y de la introducción de productos al mercado. Dentro de sus nuevos elementos se encuentran: sistema de recompensas de la universidad, recursos dedicados a la transferencia tecnológica, habilidades de las oficinas de transferencia tecnológica, comprensión cultural, flexibilidad de la universidad, comercialización formal y comercialización informal y transferencia de conocimientos (Siegel, Waldman, Atwater y Link, 2004).

La propuesta de estos nuevos elementos surgen para fortalecer el proceso de transferencia tecnológica y minimizar obstáculos que retardan la comercialización de la tecnología deteriorando la competitividad, como barreras culturales, diferencias entre universidad, académicos y empresas, personal que trabaja en las oficinas de transferencia tecnológica y remuneración al personal académico que participa en el proceso (Siegel et al., 2004).

Para hacer frente a las barreras anteriores, se incluye el elemento de cultura (idiosincrasia) que se define como el acumulado de valores, normas y creencias que son compartidos por los integrantes de un grupo y que permean las apreciaciones y conductas de los integrantes de ese grupo en particular, además de proponer la flexibilidad universitaria, contrarrestar las diferencias entre universidad, los académicos y las empresa donde se busca encontrar un punto de convergencia de agendas entre universidades y empresas; de igual manera, se suma el sistema de recompensas, pues, con una mayor asignación de recursos, aumenta la creación de patentes (Siegel et al., 2004). De acuerdo con López (2010), este modelo que se puede apreciar en la figura 2 toma el recurso humano como un factor preponderante en la comercialización. 
Figura 2. Modelo dinámico.

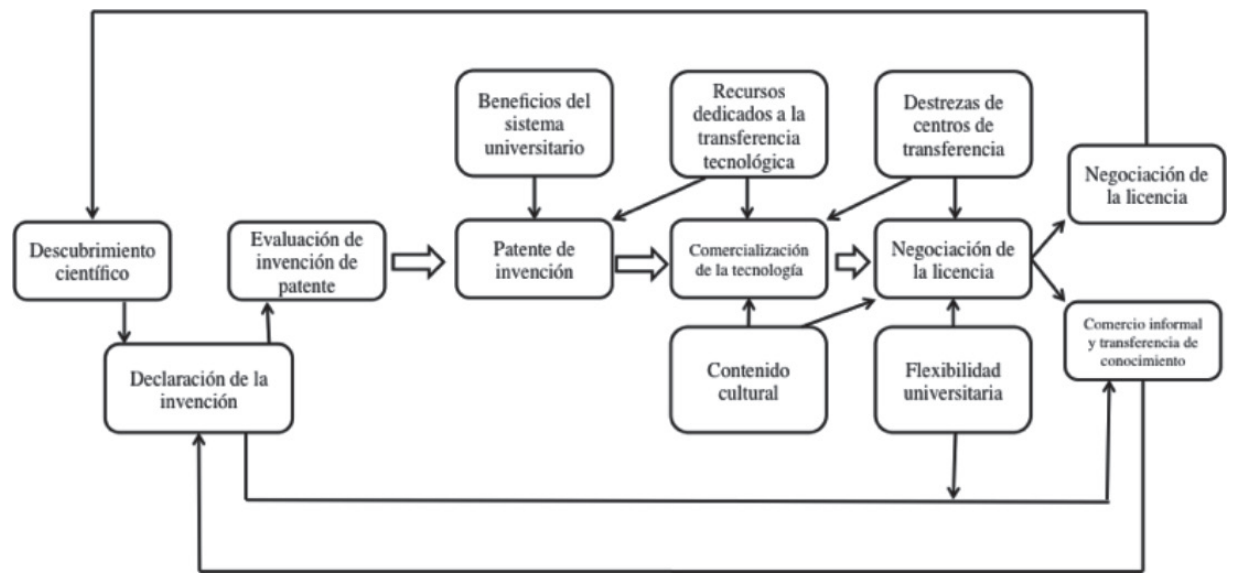

\subsubsection{Modelo triple hélice}

El modelo denominado triple hélice fue una propuesta de Etzkowitz y Leydesdorff (2000), en el cual se busca la integración de tres entes: 1) universidad, 2) empresa y 3) gobierno, con el objetivo de fijar políticas encaminadas al desarrollo de la tecnología e investigación. Esta vinculación tiene el propósito de propiciar una participación equitativa de estas entidades para restar un poco de protagonismo a la Administración pública a fin de sumarlo al vínculo de la universidad-empresa (García, Gualdrón y Bolívar, 2013; Etzkowitz y Leydesdorff, 2000).

Esta propuesta de transferencia tecnológica se gesta en la universidad en la búsqueda de la aplicación del conocimiento académico al contexto empresarial y surge de la necesidad de la insuficiencia del modelo lineal, proponiendo un modelo con características iterativas para generar innovación con participación de las universidades a través de entablar vinculación recíproca de las tres entidades (universidad, empresa y estado). Su objetivo es propiciar un contexto de innovación para la concepción de empresas de base tecnológica (spin off), a fin de detonar el crecimiento de la economía, sustentado en conocimiento en la vinculación estratégica con el sector empresarial, cetros de investigación por parte de universidades y del sector gubernamental (Etzkowitz y Zhou, 2008; Loria, 2009). 
Por tanto, para este modelo, las organizaciones demandan desarrollo tecnológico, satisfaciendo dicha necesidad a través de acercarse a centros universitarios y de investigación para hacerse de tecnología. Por otro lado, el Estado funge como generador de un contexto que facilite esta interacción - entre universidad y empresa - a través del desarrollo de políticas públicas encaminadas a promover la investigación como un detonante para el desarrollo tecnológico por medio de programas de financiamiento (García, Gualdrón y Bolívar, 2013, Loria, 2009; Etzkowitz y Leydesdorff, 2000).

Los elementos clave considerados por el modelo son las tres entidades: universidad, empresa y Estado; de manera secundaria considera el entorno, este conjunto de elementos focalizados en el mercado (García, Gualdrón y Bolívar, 2013). Asimismo, se dejan factores esenciales retomados por otros modelos como el contexto cultural (idiosincrasia). En la figura 3, se puede apreciar el modelo.

Figura 3. Modelo de la triple hélice.

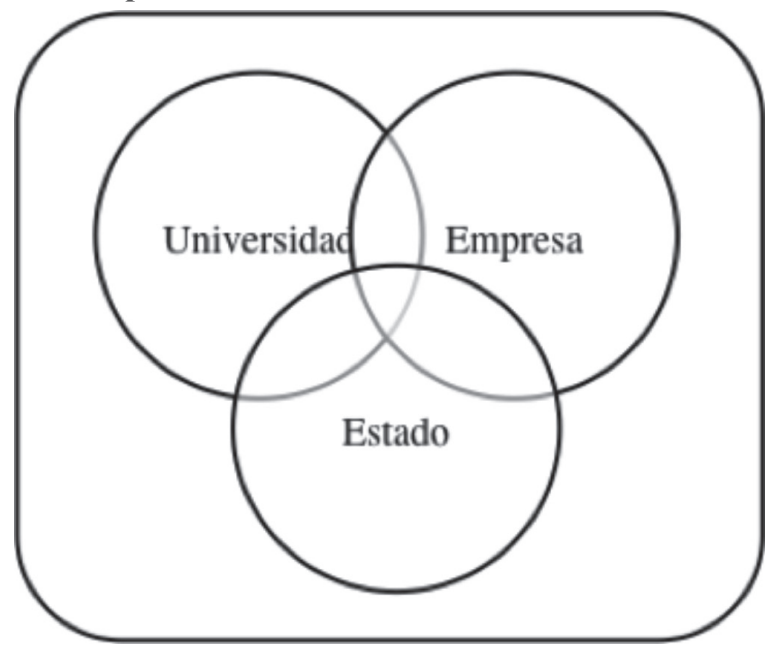

Fuente. Etzkowitz y Leydesdorff (2000).

\subsubsection{Modelo latinoamericano}

El modelo descrito en este apartado obedece a una adaptación del modelo de triple hélice para América Latina, definido como una táctica para que el conocimiento académico sea transferido a las organizaciones pudiendo 
gestionarlo a fin de generar un resultado de propiedad intelectual, estimulando a las universidades a desarrollar un entorno de innovación para acrecentar la capacidad tecnológica (Solleiro y Castañón, 2008).

De acuerdo con Solleiro y Castañón (2008), los elementos clave que determinan un proceso exitoso de transferencia tecnológica bajo este modelo es la edificación de credibilidad ante el entorno empresarial a través de mostrar experiencias, acciones acumuladas y haciendo perfectibles sus proceso. En la figura 4, se aprecian de manera detallada los factores esenciales en el modelo descrito, sin embargo, es importante señalar que el modelo da preponderancia a la interacción de siete elementos clave: universidad, Estado, empresa, propiedad intelectual, actividades de vinculación, creación de empresas y el mercado.

Figura 4. Modelo latinoamericano.

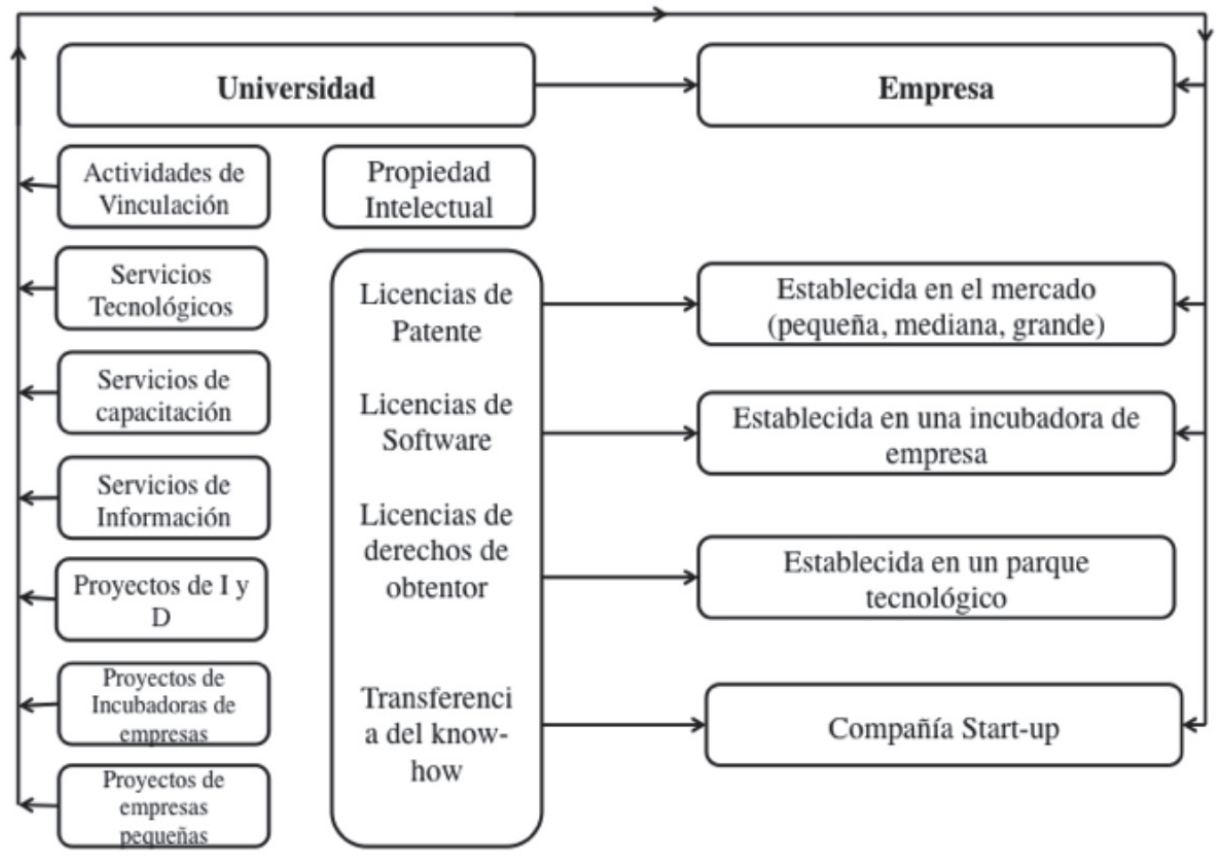

Fuente. Solleiro y Castañón (2008). 


\subsubsection{Modelo pentahélice}

El modelo de la triple hélice propuesto por Etzkowitz y Leydesdorff (2000) ha sufrido varias metamorfosis iniciado con una tríada de hélices (modelo descrito con anterioridad), hasta su más reciente versión: pentahélice. El objetivo de este modelo es ir más allá de la vinculación universidad-empresa-Estado; se buscar innovar a través de desarrollar conocimiento cooperativo, integrando la necesidad económica, la sociedad civil y la sustentabilidad del medio ambiente para hacer frente al cambio climático (Carayannis y Campbell, 2010).

De acuerdo con Carayannis y Campbell (2010) y Leydesdorff (2012), la quinta hélice representa la inclusión del entorno natural al modelo, estableciendo el medio ambiente como elemento central en el proceso para generar conocimiento e innovación encaminados a salvaguardar, preservar y revitalizar a la población mundial a través de tecnología verde que se adecúe a los desafíos del cambio climático; entonces, este modelo busca la ecoinnovación respaldada por ecoempresarios.

El pentahélice hace del conocimiento su elemento clave catalizador del progreso a través de interacción con la sociedad, intercambio de académicos entre Estados con el objetivo de suscitar y concebir un sistema cooperativo de conocimiento, del know-how (saber como) en una sociedad, de la economía y de innovar en pro de un desarrollo en favor del medio ambiente (Carayannis y Campbell, 2010; Leydesdorff, 2012).

Los elementos que constituyen este modelo, según Leydesdorff (2012), son sistema de educación, sistema económico, entorno natural, medios y cultura (idiosincrasia) y el sistema político. El sistema educativo está representado por la academia: instituciones, profesores, investigadores, estudiantes, empresarios, es decir, el capital humano. El sistema económico hace referencia al capital económico, y sus elementos representativos son la industria, los servicios y el sistema bancario. El entorno natural es el ecosistema, elemento clave que permite un desarrollo sustentable, sus componentes son los recursos naturales, animales; los medios y la cultura (idiosincrasia), donde se conjuntan los medios de comunicación (televisión, periódico, radios, redes sociales) con la cultura (valores, tradiciones, usos, costumbres). Finalmente, el sistema político, el cual da dirección a una nación para construir su presente y 
futuro, elemento que considera leyes, planes políticos. En la figura 5, se puede apreciar el modelo.

Figura 5. Modelo pentahélice.

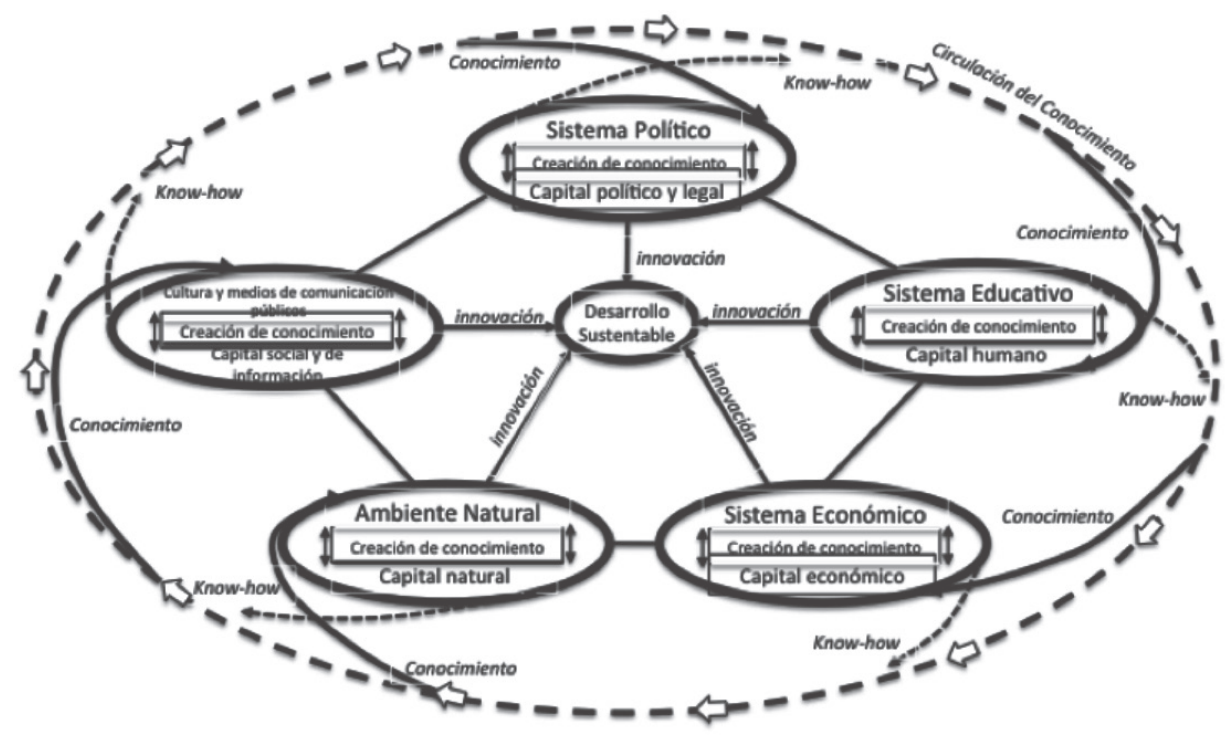

Fuente. Leydesdorff (2012) y Carayannis y Campbell (2010).

\subsubsection{Modelo European Technology Transfer Guide to Best Practice}

El acervo de proyectos europeos centrados en transferir la tecnología generaron experiencia que se tradujo en una guía europea con lo mejor de las prácticas en transferencia tecnológica, que hoy en día fungen como un modelo que consta de seis etapas: 1) búsqueda, 2) evaluación, 3) acercamiento, 4) estrategia, 5) desarrollo y 6) explotación, con el objetivo de que las innovaciones se comercialicen teniendo en cuenta proveedores, receptores tecnológicos y actores para la comercialización. A continuación, se describe el proceso de transferencia tecnológica propuesto por este modelo, según López (2010):

La primera etapa corresponde a la búsqueda, sus elementos preponderantes están representados por: vigilar las tecnologías, revisar artículos científicos, analizar la propiedad intelectual. La base de esta etapa es la información, se debe tener precisión de búsqueda y su relación con la naturaleza del proyecto es de suma importancia. (López, 2010). 
La segunda fase corresponde a la evaluación centrada en revisar a fondo particularidades de los actores implicados en el proceso de transferencia tecnológica (proveedores y receptores tecnológicos), con el objetivo de establecer una planeación estratégica. La evaluación para los proveedores se focaliza en los elementos de tiempo estimado para el desarrollo de la innovación y su transferencia de conocimiento, protección intelectual, metodología de investigación, escalamiento de la innovación. Respecto del receptor, se evalúa factibilidad financiera, tiempo para que la innovación se pueda explotar, barreras de entrada de la tecnología y el el entorno. Conjuntamente, para proveedor y receptor se evalúa el aspecto legal, justificación y motivación de la innovación, entre otros (López, 2010).

La tercer fase es denominada acercamiento, aquí se precisa una reunión oficial y física entre proveedores y receptores tecnológicos para precisar calendarios de trabajo donde se establecen compromisos, entregas, así como convenios de confidencialidad, acuerdos específicos y objetivos de los proyectos (López, 2010).

La cuarta fase es la estrategia, donde se establece un plan estratégico financiero, mercadológico, de negocio para la explotación de la innovación, asimismo, se establece el tiempo de duración del proyecto y la forma en que se llevará su gestión (López, 2010).

La quinta fase es el desarrollo, que está vinculada a la anterior, pues aquí es donde de manera detallada se desarrollan los planes estratégicos propuestos en la cuarta fase, asimismo, se comienzan a hacer el prototipo, pruebas piloto para que lo que devenga de esta fase esté listo para su explotación (López, 2010).

Finalmente, la sexta etapa ocurre cuando se pone en marcha la innovación surgida del proyecto para su comercialización e integración en un proceso de producción por parte del receptor de la tecnología, así se puede decir que se llevó a cabo una transferencia tecnológica exitosa. En esta etapa, también se hace evaluación posaplicación de la tecnología en el mercado o en proceso productivo. La peculiaridad de este modelo es la inclusión de la evaluación en cada una de sus fases, que hace de la evaluación una actividad permanente durante todo el proceso de transferencia tecnológica con una herramienta que 
habilita el paso para la siguiente fase (López, 2010). En la figura 5, se puede apreciar el modelo.

Figura 5. Modelo European Technology Transfer Guide to Best Practice.

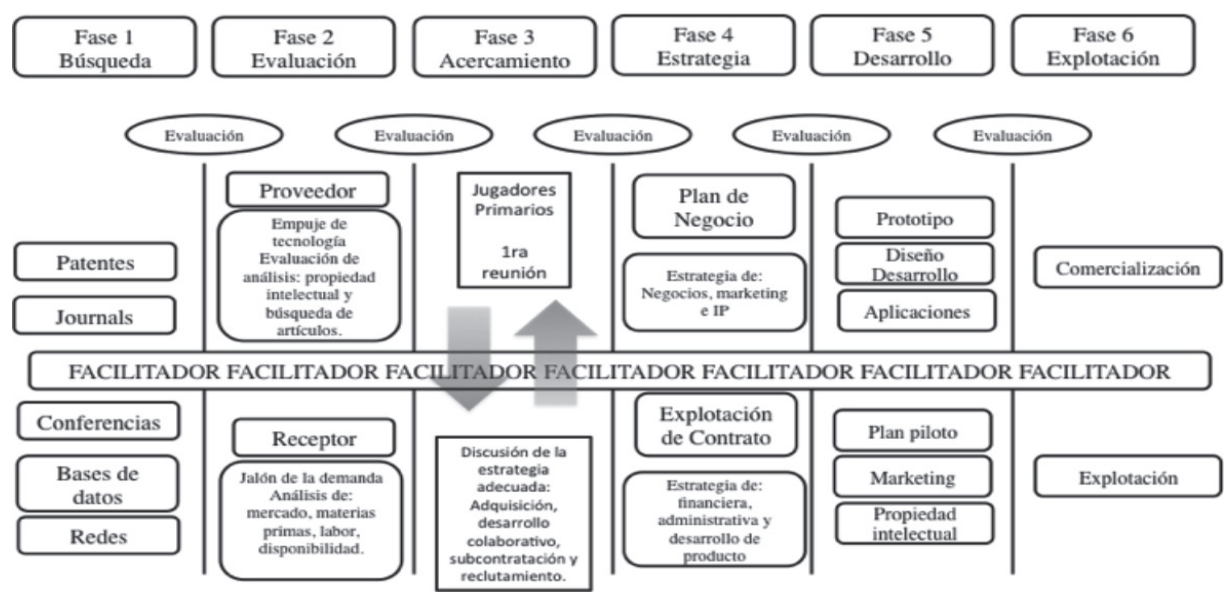

Fuente. López (2010).

\subsection{La idiosincrasia en la transferencia tecnológica}

Castro, Fernández, Pérez y Criado (2008) mencionan que los cambios tecnológicos resultan de una tecnología local o de un proceso de transferencia tecnológica extranjera; para América Latina, esta última suele ser la más recurrente, es decir, el cambio tecnológico es gestado en países desarrollados para ser transferido a los países en vías de desarrollo, lo cual resulta un proceso complejo, pues se habla de que el proveedor y receptor de la tecnología tienen características sociales, económicas, culturales y políticas desiguales.

Llevar a cabo un proceso de transferencia tecnológica exitoso actualmente representa que el receptor se inmiscuya en un proceso de aprendizaje para que pueda absorber la tecnología y la optimice. Las investigaciones en este tema han señalado que poseer una tecnología no es garantía para que sea usada de manera efectiva, por tanto, requiere este proceso de aprendizaje, absorción y optimización, aunado a mediar esas diferencias sociales, económicas, culturales y políticas (Molero, 2008). 
Según Molero (2008) y Castro et al. (2008), el factor cultural tiene una relación estrecha con la tecnología, pues la idiosincrasia entre proveedor y receptor tecnológico es diferente, lo cual puede provocar fallas al acoplar la tecnología. Podemos definir la idiosincrasia de acuerdo con Borja (2012):

La manera de ser de las personas y de los pueblos. Es el temperamento y carácter de ellos. Es el conjunto de rasgos espirituales y físicos de los individuos y de las colectividades. Se dice que algo es idiosincrásico cuando pertenece, de modo característico, a una persona o a una sociedad. Cuando forma parte de su modo de ser. Ese modo de ser es fruto de largos años de convivencia, que da a los individuos percepciones comunes sobre el bien y el mal, sobre lo correcto y lo equivocado, sobre lo apropiado y lo inapropiado, sobre lo hermoso y lo feo. (p. 1036).

Siguiendo con Borja (2012), argumenta que los elementos condicionantes y moldeadores del ser son la historia, las tradiciones, los usos, las costumbres, la cultura, la religión, el entorno, el sistema económico y productivo, factores que generan uniformidad en el individuo o un grupo de individuos determinando una particular forma en el pensamiento y actuación de estos.

La idiosincrasia representa la identidad de una persona, región, país o etnia, por tanto, el cambio tecnológico local conlleva la identidad idiosincrasia - del país desarrollador; el receptor debiera llevar un proceso de aprendizaje, absorción y optimización de la tecnología acordes con su idiosincrasia para que exista una transferencia tecnológica exitosa. 


\section{Método}

Dara llevar a cabo este trabajo, se realizó una revisión bibliográfica en bases - electrónicas de libros y revistas especializadas, centrando la búsqueda en tópicos sobre transferencia tecnológica e idiosincrasia. Sus resultados fueron organizados en fichas que incluyen una redacción sintáctica del documento con el objetivo de tener un orden para el análisis de la información, por tanto, se hace referencia a una investigación documental (Hoyos, 2000).

Una vez obtenida la información, se realizó un análisis de los principales modelos de transferencia tecnológica en sus etapas para identificar el lugar que asume la idiosincrasia en los modelos existentes. Asimismo, la revisión de la temática sobre la idiosincrasia permitió identificar la importancia y relevancia de este concepto en transferencia tecnológica (Gómez, Navas, Aponte, Betancourt, 2014).

\section{Resultados}

Tn aparatos anteriores, se describió la idiosincrasia - factor culturalcomo un elemento esencial para el éxito de la transferencia tecnológica, asimismo se describieron los principales modelos de transferencia tecnológica, por tanto, este apartado tiene como objetivo analizar el lugar que asume la idiosincrasia en los modelos existentes. Para ello, en la tabla 1, se describirán los principales elementos retomados por cada propuesta metodológica. 
Tabla 1. Descripción de los modelos de transferencia tecnológica

\begin{tabular}{|c|c|c|}
\hline Modelo & Elementos & Dimensión cultural \\
\hline Lineal & $\begin{array}{l}\text { - Investigación básica } \\
\text { - Investigación aplicada } \\
\text { - Desarrollo } \\
\text { - Producción } \\
\text { - Comercialización }\end{array}$ & No considera \\
\hline Dinámico & $\begin{array}{l}\text { - Descubrimiento científico } \\
\text { - Evaluación de la invención y patente } \\
\text { - Patente de la invención } \\
\text { - Comercialización de la tecnología } \\
\text { (dimensión cultural) } \\
\text { - Negociación de la licencia } \\
\text { - Declaración de la invención }\end{array}$ & Sí considera \\
\hline Triple hélice & $\begin{array}{l}\text { - Universidad } \\
\text { - Empresa } \\
\text { - Estado }\end{array}$ & No considera \\
\hline Latinoamericano & $\begin{array}{l}\text { - Universidad } \\
\text { - Empresa } \\
\text { - Estado } \\
\text { - Propiedad intelectual } \\
\text { - Actividades de vinculación } \\
\text { - Creación de empresas } \\
\text { - Mercado }\end{array}$ & No considera \\
\hline Pentahélice & $\begin{array}{l}\text { - Sistema de educación } \\
\text { - Sistema económico } \\
\text { - Entorno natural } \\
\text { - Medios y cultura } \\
\text { - Sistema político }\end{array}$ & Sí considera \\
\hline $\begin{array}{c}\text { European } \\
\text { Technology } \\
\text { Transfer Guide to } \\
\text { Best Practice }\end{array}$ & $\begin{array}{l}\text { - Búsqueda } \\
\text { - Evaluación } \\
\text { - Acercamiento } \\
\text { - Estrategia } \\
\text { - Desarrollo } \\
\text { - Explotación }\end{array}$ & No considera \\
\hline
\end{tabular}

Fuente. Elaboración propia a partir de Siegel et al. (2004), Etzkowitz y Leydesdorff (2000), Solleiro y Castañón (2008), López (2010), Leydesdorff (2012) y Carayannis y Campbell (2010). 
Como se puede observar en la tabla 1 , los modelos de transferencia tecnológica se centran en lograr una innovación sujeta a explotación comercial, que genere una ventaja competitiva llevando a cabo un proceso que cuenta con ciertos elementos como común denominador, de acuerdo con Solleiro y Castañón (2008): investigación básica, declaración de la invención, evaluación de la tecnología, protección intelectual, plan detallado de comercialización de la tecnología, negociación del contrato de licencia y seguimiento; sin embargo, la parte cultural —idiosincrasia — está siendo soslayada, pues solo dos modelos de los descritos la incluye en sus elementos.

\section{Conclusiones}

7 s pertinente reflexionar acerca de los factores a los cuales se les ha dado menor importancia o bien han sido soslayados en los procesos de transferencia tecnológica, como es el caso de la dimensión cultural representada por la idiosincrasia, concepto esencial, de acuerdo con Molero (2008), para un exitoso proceso de transferencia tecnológica. Su importancia radica en el hecho de que el cambio tecnológico es comúnmente originado en países desarrollados para ser transferido a los países en vías de desarrollo, lo cual resulta un proceso complejo, pues se habla de que el proveedor y receptor de la tecnología tienen características sociales, económicas, culturales, políticas muy distintas.

Según Molero (2008), ostentar tecnología no otorga garantía de que sea usada efectivamente, sino que es necesario lograr su aprendizaje, absorción y optimización, aunado a que la tecnología tenga la identidad del receptor, es decir, el modelo de transferencia tecnológica debe tener en cuenta la historia, las tradiciones, los usos, las costumbres, la cultura, la religión, el entorno económico y productivo de quien la recibirá, de lo contrario, según Castro et al. (2008), puede provocar fallas al acoplar la tecnología. 
Una vez expuesta la importancia y relevancia de la idiosincrasia en la transferencia tecnológica, este artículo de reflexión pretende contribuir en sugerir vetas de estudio encaminadas a la inclusión de la idiosincrasia como un elemento esencial que permitirá al receptor tener una tecnología que responda a las necesidades de su entorno y así construir ventajas competitivas. Asimismo, se contribuye en resumir y analizar un tema relevante en la gestión tecnológica como lo es la transferencia tecnológica proporcionando al lector una puesta al día sobre conceptos que se encuentran en una constante evolución. 


\section{Referencias}

Aceytuno, M. T., Cáceres, F. R. (2012). Los modelos europeos de transferencia tecnológica universidad-empresa. Revista de Economía Mundial, 31, 215238.

Borja, R. (2012). Enciclopedia de la política (t. 2). México: Fondo de Cultura Económica. Recuperado de https://goo.gl/87EUZK

Bunge, M. (2012). Buscar la filosofía en las ciencias sociales. México: Panamericana.

Carayannis, E. G. y Campbell, D. F. J. (2010). Triple helix, quadruple helix and quintuple helix and how do knowledge, innovation, and environment relate to each other? International Journal of Social Ecology and Sustainable Development, 1(1), 41-69.

Castells, M. (1999). La era de la información: economía, sociedad y cultura. México: Siglo XXI.

Castro Martínez, E., Fernández de Lucio, I., Pérez Marín, M. y Criado Boado, F. (2008). La transferencia de conocimientos desde las humanidades: posibilidades y características. Arbor, 184(732), 619-636.

European Commission, DG Enterprise (2004). Improving institutions for the transfer of technology from science to enterprise. Typology of TTIs in Europe.

Etzkowitz, H. y Leydesdorff, L. (2000). The dynamics of innovation: From National Systems and "Mode 2" to a Triple Helix of university-industrygovernment relations. Research Policy, 29(2), 109-123. Recuperado de https://goo.gl/5fKNry

Etzkowitz, H. y Zhou, C. (2008). Introduction to special issue Building the entrepreneurial university: A global perspective. Science and Public Policy, 35(9), 627-635.

Fundación COTEC (2001). Gestión de la innovación y la tecnología en la empresa. Madrid: Fundación COTEC. 
García Mogollón, J. M., Gualdrón Guerrero, C. A. y Bolívar León, R. (2013). Diseño de un modelo de transferencia universidad-empresa para la I+D generado por grupos de investigación de la Universidad de Pamplona. Revista Escuela de Administración de Negocios, 74, pp. 106-119.

Gómez-Luna, E., Fernando-Navas, D., Aponte-Mayor, G. y BetancourtBuitrago, L. A. (2014). Metodología para la revisión bibliográfica y la gestión de información de temas científicos, a través de su estructuración y sistematización. Dyna, 81(184), 158-163. Recuperado de https://goo.gl/ Rp1grB

Hoyos Botero, C. (2000). Un modelo para investigación documental: guía teórico-práctica sobre construcción de Estados del Arte con importantes reflexiones sobre la investigación. Medellín: Señal Editora.

Leydesdorff, L. (2012). The triple helix, quadruple helix,..., and an N-tuple of helices: Explanatory models for analyzing the knowledge-based economy? Journal of the Knowledge Economy, 3(1), 25-35.

Loaiza Becerra, M. (2004). La transferencia tecnológica en Japón: conceptos y enfoques. México Universidad Autónoma de Nuevo León.

López Fierros, H. S. (2010). El proceso de transferencia tecnológica: caso UPDCE (Tesis de maestría, Instituto Politécnico Nacional, México).

Loria, M. M. (2009). La percepción de la transferencia de tecnológica de las IES en el área de mecánica-electrónica en Mérida, Yucatán. Ponencia presentada en Congreso Nacional de Tecnología Industrial, Universidad Tecnológica Metropolitana, México.

Molero, J. (2008). La transferencia tecnológica revisitada: conceptos básicos y nuevas reflexiones a partir de un modelo de gestión de excelencia. Arbor, 184(732), 637-651. Recuperado de https://goo.gl/dra67h

Ohmae, K. (1990). El poder de la tríada: panorama de la competencia mundial en la próxima década. México: McGraw-Hill Interamericana.

Porter, M. E. (2011). Competitive advantage of nations: Creating and sustaining superior performance. Nueva York: Simon and Schuster. 
Siegel, D. S., Waldman, D. A., Atwater, L. E. y Link, A. N. (2004). Toward a model of the effective transfer of scientific knowledge from academicians to practitioners: Qualitative evidence from the commercialization of university technologies. Journal of Engineering and Technology Management, 21(1), 115-142.

Smith, K. (1995). Les interactions dans les systémes de connaissances: justifications, conséquences au plan de l'action goubernamentale et méthodes emperiques. STI Revue, 16, 75-114.

Solleiro, J. L. y Castañón, R. (coords.) (2008). Gestión tecnológica: conceptos y prácticas. México: Plaza y Valdés.

Sosa Pérez, J. A. (2014). América Latina vs. la transferencia tecnológica y desarrollo. Ciencia y Sociedad, 39(2), 269-286.

Soto Noriega, M. (2006). Transferencia tecnológica, $\measuredangle$ Qué podemos aprender de la experiencia internacional? Journal of Technology Management \& Innovation, 1(3), 1-3.

Stiglitz, J. (2002). El malestar de la globalización. Buenos Aires: Taurus.

Tezanos, J. F. (2001). La sociedad dividida: estructuras de clase y desigualdades en las sociedades tecnológicas. Madrid: Biblioteca Nueva.

United Nations Conference on Trade and Development (2003). International investment instruments: A compendium (vol. 12). New York, Geneva: United Nations. Recuperado de https://goo.gl/RFfFPv

Villavicencio, D. y Arvanitis, R. (1994). Transferencia de tecnología y aprendizaje tecnológico: reflexiones basadas en trabajos empíricos. El Trimestre Económico, 61(2), 257-279. Recuperado de https:/goo.gl/ yDS9kd 